\title{
O PAPEL DAS SERVENTIAS EXTRAJUDICIAIS NO APRIMORAMENTO DO ACESSO À JUSTIÇA
}

\section{Daiane Schwabe Minelli * Rozane da Rosa Cachapuz **}

Resumo: O presente trabalho busca analisar a atuação das serventias extrajudiciais dentro do processo de desjudicialização e seu enquadramento na terceira onda renovatória de acesso à justiça. Elenca as atividades a elas atribuídas legalmente, antes afetas à exclusiva tutela jurisdicional, e analisa as principais caraterísticas que as tornam aptas a realizá-las, de forma mais célere, efetiva e menos onerosa, cooperando com o aprimoramento do acesso à justiça.

Palavras-chave: Acesso à justiça. Desjudicialização. Serventias extrajudiciais.

\section{THE ROLE OF OUT-OF-COURT SERVICES IN IMPROVING THE ACCESS TO JUSTICE}

\begin{abstract}
This paper aims to analyze the role of the out-of-court services within the process of disjudicialization and its placement in the third wave of reform of the access to justice. It lists the activities legally attributed to them, previously related to exclusive jurisdictional protection, and analyzes the main characteristics that make them capable of performing them, in a faster, more effective and less costly way, cooperating with the improvement of the access to justice.
\end{abstract}

Keywords: Access to justice. Disjudicialization. Out-of-court Services.

\section{INTRODUÇÃO}

A sociedade é fonte de constantes conflitos, os quais, em decorrência do exercício do direito fundamental de acesso à justiça, garantido constitucionalmente, têm por destino tradicional o Poder Judiciário. É sabido, entretanto, que o crescente volume de processos, muitas vezes, de baixa complexidade, torna esse sistema cada vez mais congestionado, moroso e ineficiente, o que acaba gerando uma significativa restrição ao direito de acesso à justiça daqueles que realmente dependem de uma resposta do Estado-juiz para a solução de seus conflitos.

\footnotetext{
* Graduada em Direito pela Universidade Estadual de Londrina (2004). Mestranda em Direito Negocial pela Universidade Estadual de Londrina. Registradora de Imóveis em Peabiru-PR. E-mail: dddaia@ hotmail.com.

** Graduada em Direito pela Universidade da Região da Campanha (1993). Mestre em Direito Negocial pela Universidade Estadual de Londrina (1998) e Doutora em Direito Internacional pela Pontifícia Universidade Católica de São Paulo (2002). Professora na Universidade Estadual de Londrina. Coordenadora dos cursos de Pós Graduação em Direito Empresarial, Direito de Família à Luz da Responsabilidade Civil, na Universidade Estadual de Londrina. E-mail: rozane_cachapuz@hotmail.com.
}

Revista Cidadania e Acesso à Justiça | e-ISSN: 2526-026X | Porto Alegre | v. 4 | n. 2 | p. 01 - 19 | Jul/Dez. 2018 
Esse cenário, somado ao alto custo de um processo judicial e à irrazoável duração do processo, deu origem à demanda por formas alternativas e mais céleres de solucionar os problemas jurídicos, as quais podem ser enquadradas sob o enfoque da denominada "terceira onda de renovação do acesso à justiça", apresentada por Cappelletti e Garth, na obra "Acesso à Justiça".

Como forma de dar efetividade a esse novo enfoque do acesso à justiça e cooperar para a desobstrução do sistema judicial, vem se concretizando o chamado "processo de desjudicialização" ou de informalização, que busca atribuir às serventias extrajudiciais, titularizadas por particulares que atuam em colaboração com o Estado, atividades antes reservadas à exclusiva tutela jurisdicional.

Nesse sentido é que vem sendo ampliado o leque de competências das serventias extrajudiciais, sendo a elas atribuídas atividades em que não se verifica a presença de litígio, como: retificação de área; separação e divórcio consensuais; partilha, inventário e adjudicação; execução extrajudicial de alienação fiduciária; usucapião extrajudicial; procedimento de regularização fundiária, entre outras.

Essa iniciativa oportuniza a opção por uma via alternativa menos onerosa e mais célere, contando com a orientação de um profissional do direito que recebe delegação do poder estatal, após devida habilitação em concurso público, para exercer atividades extrajudiciais de notas ou registros públicos, tornando-se portador de fé pública e atuando sob a fiscalização do Poder Judiciário.

Soma-se a essas características o fato de as serventias extrajudiciais possuírem vasta capilaridade territorial, o que proporciona facilidade de acesso aos interessados até mesmo nos menores municípios e distritos do país, onde poderão ver seus problemas jurídicos resolvidos de forma mais célere e menos onerosa e burocrática, porém não menos técnica.

Com relação à metodologia escolhida para o desenvolvimento deste trabalho, foi utilizada a pesquisa bibliográfica para coleta e análise dos dados, e como fontes de pesquisa explicativa foram selecionados, dentre outros, materiais advindos de livros e textos normativos.

\section{ACESSO À JUSTIÇA E SUAS ONDAS RENOVATÓRIAS}

Revista Cidadania e Acesso à Justiça | e-ISSN: 2526-026X | Porto Alegre | v. 4 | n. 2 | p. 01 - 19 | Jul/Dez. 2018 
O direito fundamental de acesso à justiça, frequentemente relacionado ao princípio da inafastabilidade da jurisdição ou da proteção judiciária, pelo qual "todos têm o direito de obter do Poder Judiciário a tutela jurisdicional adequada” (NERY JÚNIOR, 2004, p. 130), costumava ser considerado apenas sob seu viés formal, ou seja, no sentido de garantir a todos o acesso aos tribunais, conforme previsão expressa no art. $5^{\circ}$, inciso XXXV, da Constituição Federal (BRASIL, 1988), que dispõe que "a lei não excluirá da apreciação do Poder Judiciário lesão ou ameaça a direito".

A conotação inicial dada àquele direito decorreu de sua própria formação histórica ${ }^{3}$, num contexto de garantia de direitos individuais, mas com as constantes transformações sociais, o acesso à justiça não pode mais resumir-se apenas ao direito de pleitear solução de conflitos perante o Poder Judiciário. Com a passagem do Estado Liberal para o Estado Social, o acesso à Justiça passou a ser reconhecido como requisito fundamental de um sistema que vise garantir - e não apenas proclamar - direitos de todos (CAPPELLETTI; GARTH, 1988, p. 68).

Nesse sentido, Suter e Cachapuz afirmam que "o direito fundamental de acesso à justiça vai além da obtenção de mera resposta do juiz, galga a uma tutela jurisdicional efetiva" (SUTER; CACHAPUZ, 2016, p. 59). Da mesma forma, conclui Sardinha ao afirmar que o termo "não pode assumir a significância exclusiva de acessibilidade ao Poder Judiciário, haja vista que o referido termo abarca também o acesso a toda uma ordem de direitos e valores" (SARDINHA, 2018, p. 17).

Assim, hodiernamente, esse direito tem se consolidado não apenas como um direito de acesso aos tribunais, mas também como direito de acesso a uma ordem jurídica justa (WATANABE, 2011, p. 385), que efetivamente proporcione uma tutela que promova a realização do direito material e voltado, essencialmente, à pacificação social (DINAMARCO, 2016, p. 20), como fim último da prestação jurisdicional.

Em razão disso é que se entende que a efetivação do direito de acesso à justiça configura condição primeira e essencial para que outros direitos fundamentais também sejam efetivados (SARDINHA, 2017, p. 17). Deve, pois, ser visto como "requisito fundamental - o

\footnotetext{
${ }^{3}$ Nos estados liberais burgueses dos séculos XVIII e XIX, o direito ao acesso à proteção judicial significava essencialmente o direito formal do indivíduo de propor ou contestar uma demanda (CAPPELLETTI; GARTH, 1988, p. 9).
}

Revista Cidadania e Acesso à Justiça | e-ISSN: 2526-026X | Porto Alegre | v. 4 | n. 2 | p. 01 - 19 | Jul/Dez. 2018 
mais básico dos direitos humanos - de um sistema jurídico moderno e igualitário que pretenda garantir, e não apenas proclamar os direitos de todos" (CAPPELLETTI; GARTH, 1988, p. 68).

Assim, além de possibilitar o ingresso de pretensões em Juízo, o direito fundamental de acesso à justiça deve ser entendido como o direito de obter um atendimento simples e adequado e uma resposta justa, célere e satisfatória do Estado, sem formalismos excessivos que acabam resultando numa maior onerosidade aos usuários.

Se por um lado mostra-se importante garantir o acesso pleno e universal a uma ordem jurídica justa, como requisito inafastável para a consolidação de um Estado Democrático de Direito, por outro, essa abertura não se mostra mais capaz de suportar a imensa quantidade de novas demandas que adentram no sistema judiciário todos os dias. Dessa forma, segundo Suter e Cachapuz, teve princípio um grande problema:

O Estado ao conceder acesso amplo e irrestrito à justiça não estava preparado para maior número de demandas nos tribunais. Assim, insatisfações e reclamações no tocante a lentidão nas resoluções dos litígios, mostraram a ingerência e a desorganização do Poder Judiciário Brasileiro a dar resposta ao cidadão e a promover a paz social (SUTER; CACHAPUZ, 2016, p. 59).

Devido à grande litigiosidade que se constata na sociedade atual, devido justamente àquela abertura trazida com a concepção material do acesso à justiça, e o crescente volume de processos, muitas vezes de baixa complexidade, o Poder Judiciário não vem sendo capaz de prestar essa tutela de forma célere e efetiva, conforme os princípios e garantias processuais e constitucionais, tornando-se cada vez mais congestionado e gerando uma significativa restrição ao direito de acesso à justiça daqueles que realmente dependem de uma resposta do Estado-juiz.

No intuito de analisar os problemas que envolvem a prestação de efetiva tutela pelos tribunais e restringem aquele direito fundamental, Mauro Cappelletti e Bryan Garth demonstram ser necessário o atendimento a duas finalidades do sistema jurídico, quais sejam, a acessibilidade igualitária a todos e a produção de resultados individual e socialmente justos (CAPPELLETTI; GARTH, 1988, p. 8). 
Para viabilizar o atendimento a essas duas finalidades, os autores propuseram no relatório final de seu "Projeto Florença" ${ }^{4}$, após um amplo estudo acerca da situação da justiça, soluções para os problemas do acesso, denominadas por eles de "ondas renovatórias" de universalização do acesso a Justiça:

A primeira solução para o acesso - a primeira "onda" desse movimento novo - foi a assistência judiciária; a segunda dizia respeito às reformas tendentes a proporcionar representações jurídicas para interesses "difusos", especialmente nas áreas da proteção ambiental e do consumidor; e o terceiro - e mais recente - é o que nos propomos a chamar simplesmente "enfoque de acesso à justiça", porque inclui os posicionamentos anteriores, mas vai muito além deles, representando, dessa forma, uma tentativa de atacar as barreiras ao acesso de modo mais articulado e compreensivo (CAPPELLETTI e GARTH, 1988, p. 28).

De forma sucinta, pode-se verificar que, levando em consideração os altos custos de um processo judicial, a primeira onda renovatória traz a necessidade de se prestar efetiva assistência judiciária às pessoas desprovidas de real capacidade financeira, para que possam ter acesso ao sistema judicial e apresentarem suas pretensões de forma adequada e igualitária perante o Estado-juiz. No Brasil, a assistência judiciária tem respaldo constitucional no inciso LXXIV, do art. $5^{\circ}$, ao determinar que "o Estado prestará assistência jurídica integral e gratuita aos que comprovarem insuficiência de recursos", e vem se consolidando pelo fortalecimento da defensoria pública.

A segunda onda renovatória tem por fim destacar a relevância da representação jurídica dos interesses difusos ou coletivos em sentido amplo, que ao serem analisados de forma molecular (WATANABE, 2009, p. 2), ou seja, tratados coletivamente, proporcionam uma solução uniforme a um número maior de pessoas, evitando a pulverização de processos, também chamada de atomização, pelo mesmo autor, e, por conseguinte, a obstrução e lentidão do sistema judicial, com demandas repetitivas e decisões divergentes para casos homogêneos.

A lentidão e a obstrução verificadas no Poder Judiciário acabam, por fim, sendo o objeto da terceira onda renovatória, que busca a remoção dos obstáculos processuais que impedem um resultado rápido, eficiente e satisfatório do conflito, e que acaba, por isso,

\footnotetext{
${ }^{4}$ O projeto Florença, coordenado por Mauro Cappelletti, em colaboração com Bryant Garth e Nicolò Trocker, foi de extrema relevância para o estudo do direito processual em diversos países, retratando, a partir de estudos empíricos, em três ondas renovatórias, os entraves para o acesso à Justiça. (MENDES; SILVA, 2015. pp. 18271858).
}

Revista Cidadania e Acesso à Justiça | e-ISSN: 2526-026X | Porto Alegre | v. 4 | n. 2 | p. 01 - 19 | Jul/Dez. 2018 
abrangendo o conteúdo das duas primeiras ondas renovatórias, preconizando uma concepção mais ampla de acesso à justiça (TARTUCE, 2018, p. 83).

Em razão do congestionamento processual que acarreta morosidade e ineficiência do sistema judicial, impossibilitando que as partes envolvidas obtenham uma resposta útil e satisfatória do Estado, novas formas de pensar a justiça e resolver os conflitos devem ser proporcionadas, na esteira dessa terceira onda renovatória, que deu um novo enfoque ao acesso à justiça, dando ênfase à atividade extrajudicial. Essa constatação foi bem explicitada por Tânia Lobo Muniz,

No momento atual, com o processo contínuo de desenvolvimento da humanidade, os meios jurisdicionais têm se mostrado insuficientes e ineficientes, levando a busca de procedimentos alternativos ao juízo estatal, menos formais, mais eficazes na resolução efetiva das questões e que possibilitem uma maior pacificação e justiça, conduzindo aos meios alternativos de resolução de conflitos (MUNIZ, 2016, p. 34).

De acordo com esse entendimento, tem-se que o Poder Judiciário não pode ser considerado a única via que conduz à Justiça, devendo ser esse acesso garantido por outros caminhos, mesmo que não judiciais, mas igualmente aptos a promover uma prestação efetiva em um tempo razoável, com segurança jurídica.

Essa busca de soluções, conforme ensinamento de Fernanda Tartuce (2018, p. 36), há de ser multifacetada, abrangendo meios variados de controvérsias, que possam ser eficazmente tratados por técnicas peculiares, com oo aprimoramento das regras processuais e o aperfeiçoamento da administração da justiça. Algumas dessas técnicas vêm sendo implementadas no chamado processo de desjudicialização.

\section{O PROCESSO DE DESJUDICIALIZAÇÃO}

O cenário de crescente judicialização somado à ineficiência e morosidade do Poder Judiciário e ao novo enfoque dado ao acesso à justiça por meio da chamada "terceira onda renovatória", além das transformações sociais que demandam cada vez mais celeridade e desburocratização, fez emergir um interesse pela implementação de técnicas alternativas, que pudessem ser realizadas extrajudicialmente por vontade dos interessados, mas que garantissem a segurança jurídica própria das decisões judiciais. 
A essa ideia, associa-se a reflexão de Kazuo Watanabe (2011, p. 2), quando analisa que a solução adjudicada que predomina no Judiciário brasileiro, por meio da sentença do juiz, não vem favorecendo o acesso a uma ordem jurídica justa, de forma efetiva, tempestiva e adequada, sendo necessária uma política pública que consiga afastar a chamada "cultura da sentença", estimulando a utilização dos meios alternativos de solução de conflitos. Nesse sentido, aduzem Cappelletti e Garth (1988, p. 67) que o novo enfoque de acesso à justiça tem um alcance muito mais amplo, devendo abranger entes externos à seara judicial:

Essa "terceira onda" de reforma, inclui a advocacia, judicial ou extrajudicial, seja por meio de advogados particulares ou públicos, mas vai além. Ela centra sua atenção no conjunto geral de instituições e mecanismos, pessoas e procedimentos utilizados, para processar e mesmo prevenir disputas nas sociedades modernas (1988, p. 67).

A opção pelos caminhos extrajudiciais de acesso à justiça, segundo Sardinha (2018, p. 39), "conferem aos cidadãos uma maior liberdade e poder de decisão sobre a forma como será solucionado o seu caso concreto, reduzindo a interferência do Estado que não mais substitui a vontade das partes por meio de uma decisão judicial”.

Essa ideia não implica na proibição de optar pela via jurisdicional para solução de problemas jurídicos, ou mesmo na substituição do Poder Judiciário, mas busca reservar a ele causas de alta complexidade e de grande repercussão social, em que sua atuação se mostra inafastável, até mesmo como ultima ratio, em analogia ao Direito Penal.

Outrossim, é importante deixar claro que tanto os procedimentos decorrentes da desjudicialização quanto a tutela jurisdicional em si, são espécies do gênero tutela jurídica, como instrumentos de proteção garantidos pelo Estado, como esclarece Belinetti (1996, p. 98) quando afirma que "a tutela jurídica significa proteção do Direito para os direitos subjetivos e qualquer forma de atuar lícita, enquanto que a tutela jurisdicional significa a proteção do Estado, com base no Direito, para esses direitos e atividades lícitas". Esses procedimentos administrativos decorrentes da desjudicialização encontram-se, portanto, no âmbito da tutela jurídica e, por conseguinte, da proteção do Estado, ao lado da tutela jurisdicional.

Nesse sentido, ao analisar o chamado processo de desjuridificação que vem ocorrendo em Portugal, mas que pode ser aplicado ao Brasil pela similitude dos sistemas, João Pedroso (2002, p. 29) entende que a desjudicialização continua a ser uma intervenção estatal nas relações sociais, porém, de forma diversa do judiciário, com a transferência da 
resolução dos litígios para as instâncias não judiciais e para as velhas profissões (notários e registradores), como consequência da "incapacidade de resposta dos tribunais à procura (aumento de pendências), ao excesso de formalismo, ao custo, à “irrazoável” duração dos processos e ao difícil acesso à justiça”.

Esse processo de desjudicialização ou informalização teve seu início identificado no Brasil já há alguns anos, e vem se desenvolvendo por meio de sucessivas alterações legislativas, as quais promoveram a atribuição de atividades antes reservadas à exclusiva tutela do Poder Judiciário às serventias extrajudiciais de notas e registro, que as executam por meio de procedimento administrativo.

O processo de desjudicialização, segundo Pedroso (2002, p. 17), decorre de um contexto de reforma da administração da justiça que, ao lado do processo de informalização, integra a chamada "desjuridificação", permitindo a prevenção de um litígio:

Na prossecução deste esforço analítico há a considerar que os processos de desjuridificação incluem ainda as categorias de "informalização da justiça" e de "desjudicialização". Estes processos inserem-se no referido quarto tipo de reformas referido inicialmente, através de criação de processos, instâncias e instituições descentralizadas, informais e desprofissionalizadas que assumem a resolução de litígios outrora privativa dos tribunais judiciais. Os conceitos de informalização e desjudicialização, em sentido amplo, manifestam-se através de diferentes realidades que permitem prevenir ou resolver um litígio, ou seja, um conflito social que dois ou mais interessados pretendam que seja dirimido sem recurso ao tribunal judicial (Pedroso, 2002, p. 18).

Passam assim, as questões de menor complexidade que envolvam direitos disponíveis e que possuem um caráter de maior consensualidade, a ser resolvidas na seara extrajudicial, capaz de promover uma considerável diminuição na propositura de novas demandas e contribuindo para o descongestionamento do sistema judicial. Por meio da desjudicialização, retiram-se da esfera exclusiva do Judiciário, as questões em que não existe conflito, em que não há lide, transferindo-as para os chamados particulares em colaboração (NOBRE, 2015, p. 1), dentre eles, especialmente, os notários e registradores.

É importante salientar que, embora as partes possam optar pela via extrajudicial para a resolução de algumas questões, isso não afasta o direito de acesso ao Judiciário e nem tira dele a competência para a análise das mesmas questões, mas garante aos cidadãos um meio alternativo para a busca de suas pretensões sem ter que submetê-las à morosidade do Judiciário (SOUZA, 2011, p. 3).

Revista Cidadania e Acesso à Justiça | e-ISSN: 2526-026X | Porto Alegre | v. 4 | n. 2 | p. 01 - 19 | Jul/Dez. 2018 
Luiz Carlos Weizenmann (2008, p. 290) lembra ainda que essa atribuição aos notários e registradores, de determinadas funções administrativas exercidas pelo Judiciário, atende aos preceitos da Reforma do Poder Judiciário, veiculada por meio da Emenda Constitucional 45/2004, no que tange à eficiência. Com a referida emenda constitucional, segundo Sardinha (2018, p. 122), foi introduzida a exigência da razoável duração do processo e dos meios que garantam a celeridade de sua tramitação, tanto no âmbito judicial como no âmbito administrativo, o que deu ainda mais força para que esse processo de desjudicialização pudesse ser concretizado.

Nessa toada, conceituando a desjudicialização dentro desse contexto da razoável duração do processo, Diogo Soares Cunha Melo afirma que "a propagação de tal tendência decorre da multiplicação de processos que afogam o Judiciário, tendo como consequência o abalo da razoável duração do processo" (MELO, 2017, p. 100).

Diante das considerações acima expostas, pode-se verificar que a desjudicialização configura um importante instrumento para descongestionar o Poder Judiciário, restando demonstrar a importância das serventias extrajudiciais no desempenho desse processo para que possa atingir os efeitos desejados, razão pela qual esses entes serão objeto de análise no tópico seguinte, juntamente com os procedimentos a elas atribuídos.

Antes de adentrar no tema das serventias extrajudiciais, é importante fazer a ressalva de que não se pretende aqui esgotar o conteúdo relativo à desjudicialização e às serventias, que serão objeto de estudo específico.

\section{AS SERVENTIAS EXTRAJUDICIAIS E AS PRINCIPAIS HIPÓTESES DE DESJUDICIALIZAÇAO NO BRASIL}

O processo de desjudicialização já vem conquistando grandes avanços no Brasil, com resultados cada vez mais efetivos, competindo às serventias extrajudiciais sua consolidação, por meio da realização de procedimentos administrativos previstos em lei. Segundo Sardinha, as serventias extrajudiciais:

têm sido enxergadas como alternativa para a efetivação do direito de acesso à justiça, em face do respaldo principiológico do Direito Notarial e Registral, além da necessidade de implementação de novos métodos de composição de 
litígios, a fim de que haja a resolução de conflitos, assegure-se a paz social e ao mesmo tempo, auxilie-se na mitigação do volume de processos apresentados ao Poder Judiciário (SARDINHA, 2018, p. 123).

Cumpre, portanto, analisar as características que tornam esses entes aptos a realizar esses procedimentos, bem como quais deles já estão sendo implementados.

\subsection{CARACTERÍSTICAS}

Primeiramente deve-se esclarecer que existem, de forma mais usual ${ }^{5}$, seis tipos de serventias extrajudiciais: Serviço de Notas, Serviço de Registro de Imóveis, Serviço de Protesto de Títulos e Documentos, Serviço de Registro de Títulos e Documentos, Serviço de Registro Civil das Pessoas Naturais e das Pessoas Jurídicas.

O regime jurídico dos notários e registradores, titulares das serventias notariais e de registro, foi estabelecido pela Lei $\mathrm{n}^{\mathrm{o}}$ 8.935/94, atendendo ao comando do art. 236 da Constituição Federal de 1988, que dispõe que "os serviços notariais e de registro são exercidos em caráter privado, por delegação do Poder Público".

Assim, verifica-se que os serviços extrajudiciais, notariais e de registro, são funções públicas, objeto de transferência por delegação, com fulcro na Constituição Federal, pelo poder público a notários e registradores após aprovação em concurso público de provas e títulos. Nesse sentido, o regime jurídico da atividade foi analisado pela primeira vez pelo Supremo Tribunal Federal, no julgamento da ADI 3151 (em 08/06/2005), do qual constou o seguinte excerto cujo teor merece transcrição:

[...] a) trata-se de atividades jurídicas próprias do Estado, e não simplesmente de atividades materiais, cuja prestação é traspassada para os particulares mediante delegação. Traspassada, não por conduto dos mecanismos da concessão ou da permissão, normados pelo caput do art. 175 da Constituição como instrumentos contratuais de privatização do exercício dessa atividade material (não jurídica) em que se constituem os serviços públicos; b) a delegação que lhes timbra a funcionalidade não se traduz, por nenhuma forma, em cláusulas contratuais; c) a sua delegação somente pode recair sobre pessoa natural, e não sobre uma empresa ou pessoa mercantil, visto que de empresa ou pessoa mercantil é que versa a Magna Carta Federal em tema de concessão ou permissão de serviço público; d) para se tornar

\footnotetext{
${ }^{5}$ Existem também os tabeliães e oficiais de registro de contratos marítimos, conforme art. $5^{0}$, da lei $\mathrm{n}^{0}$ 8.935/94, os quais, por não constituírem número expressivo, não farão parte da análise deste trabalho.
}

Revista Cidadania e Acesso à Justiça | e-ISSN: 2526-026X | Porto Alegre | v. 4 | n. 2 | p. 01 - 19 | Jul/Dez. 2018 
delegatária do Poder Público, tal pessoa natural há de ganhar habilitação em concurso público de provas e títulos, não por adjudicação em processo licitatório, regrado pela Constituição como antecedente necessário do contrato de concessão ou de permissão para o desempenho de serviço público; e) são atividades estatais cujo exercício privado jaz sob a exclusiva fiscalização do Poder Judiciário, e não sob órgão ou entidade do Poder Executivo, sabido que por órgão ou entidade do Poder Executivo é que se dá a imediata fiscalização das empresas concessionárias ou permissionárias de serviços públicos. Por órgãos do Poder Judiciário é que se marca a presença do Estado para conferir certeza e liquidez jurídica às relações inter-partes, com esta conhecida diferença: o modo usual de atuação do Poder Judiciário se dá sob o signo da contenciosidade, enquanto o invariável modo de atuação das serventias extra-forenses não adentra essa delicada esfera da litigiosidade entre sujeitos de direito; f) as atividades notariais e de registro não se inscrevem no âmbito das remuneráveis por tarifa ou preço público, mas no círculo das que se pautam por uma tabela de emolumentos, jungidos estes a normas gerais que se editam por lei necessariamente federal [...] (STF Pleno. ADIN - MT n ${ }^{0}$ 3.151-1. Rel. Min. Carlos Britto. Julg. 08.06.2005. DJ. 28.04.2006).

O exercício das funções notariais e de registro é realizado de forma privada, por pessoas físicas, profissionais do direito que, aprovados em concurso público, recebem delegação do Poder Público e com ele atuam em regime de colaboração, daí ser-lhes atribuída, por alguns, a denominação de agentes públicos da espécie particulares em colaboração com o Estado (SILVA, 2016, p. 6).

Os serviços prestados por esses agentes são dotados de publicidade, autenticidade, segurança e eficácia, conforme previsão expressa do art. $1^{\circ}$ da Lei ${ }^{\circ}$ 8.935/1994, sendo os atos por eles realizados resguardados pela fé pública, ou seja, uma forte presunção de sua veracidade (CENEVIVA, 2014, p. 24).

Atuam os notários e registradores, assim, de forma preventiva, assegurando a autenticidade, segurança, eficácia e publicidade dos atos jurídicos, como forma de manter a paz social (SARDINHA, 2018, p. 58), exercendo ainda um controle da legalidade dos atos que lhe forem submetidos. Por meio de sua atuação, será conferida segurança jurídica ao ato realizado, advinda da fé pública da qual são investidos e do efeito da publicidade.

A segurança jurídica decorre ainda da independência e da imparcialidade garantidas legalmente aos agentes delegados, que os permitem atuar de forma imune a pressões externas, conforme a lei, e de forma equidistante das partes envolvidas, prevenindo eventuais litígios.

Sobre a segurança jurídica, destaca MELO: 
Independentemente do movimento de desjudicialização, a conduta é pautada em uma segurança jurídica preventiva, uma vez que pratica atos dotados de profilaxia e impedem que demandas cheguem ao Judiciário. Ao tabelião cabe o papel da segurança jurídica dinâmica, pois é responsável pela formação do título, enquanto o registrador é responsável pela segurança jurídica estática, mantendo o fólio real confiável e livre de anomalias extrínsecas (MELO, 2017, p. 101).

Soma-se a essas características legais o fato de as serventias extrajudiciais possuírem vasta capilaridade territorial, o que proporciona facilidade de acesso aos interessados até mesmo nos menores municípios do país, onde poderão ser atendidos de forma mais célere e menos burocrática e com maior identificação e sensação de acolhimento.

Nesse sentido, adiciona Silva (2016, p. 109), que as serventias extrajudiciais têm a potencialidade de alcançar "todos os distritos de todas as cidades brasileiras, sendo verdadeiro longa manus do Estado, desafogando o Estado Juiz nas ações relativas aos direitos disponíveis, e, mesmo os indisponíveis transacionáveis", sem custo para os cofres públicos, contribuindo para o processo de desjudicialização, de forma eficaz e menos onerosa.

Diante dessas características que envolvem a atividade extrajudicial, exercida pelos notários ou registradores, verifica-se que os procedimentos decorrentes do movimento de desjudicialização podem ser por eles materializados de forma adequada e satisfatória, de forma a prevenir e evitar futuros litígios, em prol da concretização do acesso a justiça.

\subsection{Hipóteses de Desjudicialização no Brasil}

Inicialmente, cumpre ressalvar que, sem qualquer pretensão de esgotar o tema, serão analisadas as hipóteses de desjudicialização existentes no Brasil, conforme o ordenamento jurídico vigente, com destaque para aos procedimentos de maior relevo.

Assim, pode-se dizer que a desjudicialização foi verificada no Brasil já no ano de 1992, com a publicação da Lei $\mathrm{n}^{\circ}$ 8.560, que autorizou o reconhecimento de paternidade diretamente nos serviços de registro civil, sendo anteriormente um procedimento judicial.

No ano de 1997, foi publicada a Lei $\mathrm{n}^{\circ}$ 9.514, alterada recentemente pela Lei $\mathrm{n}^{\circ}$ 13.465/17, que trata de Alienação Fiduciária e permite que os procedimentos envolvendo a execução do devedor nesses contratos, fossem realizados por meio do Serviço de Registro de 
Imóveis, bem como os serviços de notificação, pelo Serviço de Registro de Títulos e Documentos.

Ainda no ano 1997, a Lei $\mathrm{n}^{\circ}$ 9.492, ao regulamentar os serviços referentes ao protesto de títulos, prevê expressamente a possibilidade de apresentação de "outros documentos de dívida", além dos títulos de crédito tradicionais, o que permite que hoje, essas serventias realizem o protesto de certidões de dívida ativa $(\mathrm{CDA})$, antes atribuídas à exclusiva e infindável tutela jurisdicional.

No ano de 2004, a Lei $n^{\circ} 10.931$ alterou os artigos 212 e 213 da Lei no 6.015/73, e passou a autorizar que fosse realizada a retificação administrativa de área diretamente no serviço de registro imobiliário (SILVA, 2016, p. 100), de ofício pelo titular ou a requerimento da parte, sendo facultada ao interessado a opção pela via jurisdicional.

No ano de 2007, ganhou merecido destaque no contexto da desjudicialização a publicação da Lei ${ }^{\circ}$ 11.441/2007, que possibilitou que inventário, partilha, separação e divórcio consensuais fossem realizados por meio de escritura pública nas serventias notariais, verificada a ausência de conflito entre as partes e a inexistência de partes menores ou incapazes (SARDINHA, 2018, p. 130). Essas escrituras não estão sujeitas à convalidação judicial e têm plena eficácia para fins de futuro registro ou averbação, perante serventias imobiliárias ou de registro civil.

Posteriormente, para fins de uniformizar entendimentos referentes à aplicação da lei $n^{0}$ 11.441/07, foi editada a Resolução $n^{o} 35$, do Conselho Nacional de Justiça, por meio da qual ficou estabelecida a opção pela via extrajudicial como uma faculdade das partes, assim como a possibilidade de desistência da via judicial e opção pela via extrajudicial, entre outros pontos que ensejavam dúvidas em sua aplicação.

A referida lei operou uma grande revolução, na medida em que, segundo Nobre (2015, p. 2), apenas essa iniciativa legislativa, que é um exemplo da desjudicialização, "foi capaz de esvaziar prateleiras no foro, do dia para noite, como nunca dantes se suspeitara ser possível”. Além disso, os processos de inventário e partilha e de divórcio consensual, que permaneciam por muitos meses nessas prateleiras da justiça comum, hoje podem ser finalizados em questão de dias.

Essa celeridade, somada a ausência de maiores constrangimentos para o casal (no caso do divórcio) e para os herdeiros do de cujus (no inventário), demonstrou que a lei se coaduna

Revista Cidadania e Acesso à Justiça | e-ISSN: 2526-026X | Porto Alegre | v. 4 | n. 2 | p. 01 - 19 | Jul/Dez. 2018 
com a justiça coexistencial, priorizando a autonomia das partes e atendendo a instrumentalidade e efetividade do processo contemporâneo (CRUZ, 2017, p. 179).

Ainda com relação à efetividade, verifica-se que, segundo dados do Colégio Notarial do Brasil (CNB), veiculados na página eletrônica do Conjur - Consultor Jurídico ${ }^{6}$, desde a entrada em vigor da Lei $n^{\circ} 11.441$, em 05 de janeiro de 2007, mais de 1,3 milhão de atos foram oficializados em tabelionatos de todo o Brasil. Isso significa que no mínimo 2 milhões de pessoas deixaram de judicializar suas pretensões perante o Poder Judiciário.

Além disso, consta ainda da referida notícia que, de acordo com informações do Colégio Notarial do Brasil, o fato de as serventias notariais terem assumido essa responsabilidade evitou um custo de $\mathrm{R} \$ 3$ bilhões à Justiça brasileira. Os valores foram calculados pela entidade com base em estudo de 2013 do Centro de Pesquisas sobre o Sistema de Justiça Brasileiro (CPJus).

São dados que impressionam, tanto no que tange à eficiência e celeridade das serventias extrajudiciais na realização desses atos, quanto na significativa economia financeira e na resolução de situações que, sem a lei $\mathrm{n}^{\circ} 11.441 / 17$, configurariam futuras demandas obstruindo consideravelmente o sistema judiciário.

Importante destacar que a lei $\mathrm{n}^{\mathrm{o}} 11.441 / 07$ foi incorporada ao Código de Processo Civil de 2015, em seus artigos 610 e 659 (inventário e partilha) e 733 (separação, divórcio e extinção de união estável). No ano de 2015, ainda no contexto do novo Código de Processo Civil, houve o reconhecimento da possibilidade de usucapião extrajudicial de bens imóveis ${ }^{7}$ em seu art. 1.084, que acrescentou o artigo 216-A à Lei $n^{\circ} 6.015 / 1973$, permitindo a sua realização inicialmente pela serventia notarial, por meio de ata notarial que ateste o tempo de posse e, em seguida, finalizando com o registro na serventia imobiliária, a requerimento da parte interessada, conforme Provimento $n^{0}$ 65/2018, CNJ.

Seguindo essa tendência de ampliação legal das competências atribuídas às serventias extrajudiciais, na esteira do processo da desjudicialização, segundo Sardinha (2018, p. 125),

\footnotetext{
6 CONJUR. Atos em cartórios retiraram 1,3 milhão de processos da Justiça. Disponível em http://www.conjur.com.br/2016-jul-25/atos-cartorios-retiraram-13-milhao-processos-justica. Acesso em 25.07.2016.

${ }^{7}$ A usucapião extrajudicial, embora configure um avanço louvável na promoção de celeridade e desobstrução do Poder Judiciário, não é inédita na legislação brasileira, tendo sido prevista na revogada Lei no 11.977/09, como relembra Nobre (2015, p. 2), embora com efeitos bastante limitados, por dar-se exclusivamente no cenário da regularização fundiária urbana, em procedimento administrativo demasiadamente complexo.
} 
“despontam no horizonte outras situações jurídicas que também poderão ser resolvidas no campo das serventias extrajudiciais, desde que presentes os requisitos legais obrigatórios".

A mais recente inovação nesse processo de desjudicialização se deu com a publicação da lei $n^{\circ} 13.465 / 17$, que regulamentou o novo procedimento de regularização fundiária, a ser realizado perante as serventias de registro de imóveis. 


\section{CONSIDERAÇÕES FINAIS}

A necessidade de busca por novos caminhos que pudessem solucionar o problema da morosidade e da ineficiência do sistema judicial encontrou respaldo, principalmente, no aprofundamento de estudos envolvendo em grande parte, as ondas renovatórias de acesso à justiça, que estimularam a busca por vias alternativas para a concretização do acesso a uma ordem jurídica justa.

As constantes transformações sociais e as crescentes demandas por celeridade e simplificação de procedimentos acabaram por possibilitar uma mudança de perspectiva com relação ao papel que as serventias extrajudiciais podem exercer na sociedade atual, como aliadas do Poder Judiciário no aprimoramento do acesso à justiça.

Se por um lado o acesso ao Poder judiciário configura direito fundamental e promove segurança jurídica, por outro não deve ser esse o destino de questões triviais, devendo a ele ser reservada a análise de questões de alta complexidade e de grande repercussão social, as quais realmente vão demandar um aprofundamento cognitivo e detalhada análise probatória.

Com relação aos problemas jurídicos de baixa ou nenhuma complexidade em que se encontra presente a consensualidade, embora assegurados pelo manto da inafastabilidade da via judicial, poderão encontrar nas vias extrajudiciais, uma resposta rápida, eficiente e mais acessível, em razão do processo de desjudicialização.

A transferência de atividades, outrora reservadas à via jurisdicional, para as serventias extrajudiciais valoriza a autonomia privada, uma vez que atribui ao arbítrio das partes a forma de condução mais adequada de seus problemas jurídicos.

Além disso, oportuniza uma via alternativa menos onerosa e mais célere, porém não menos efetiva e segura, posto que titularizadas por agentes portadores de fé pública e que atuam sob a fiscalização do Poder Judiciário.

Outro fator que deve ser considerado é a proximidade que essas serventias possuem da população, proporcionando fácil acesso nas mais variadas regiões do país, inclusive em locais que não dispõem de fóruns judiciais, devido a sua vasta capilaridade territorial.

São ainda significativos os resultados econômicos que as medidas decorrentes da desjudicialização vêm apresentando, mas o maior destaque deve ser atribuído aos resultados sociais, uma vez que as medidas que vêm sendo concretizadas, no que tange principalmente à

Revista Cidadania e Acesso à Justiça | e-ISSN: 2526-026X | Porto Alegre | v. 4 | n. 2 | p. 01 - 19 | Jul/Dez. 2018 
lei $n^{o}$ 11.441/07, tem cooperado consideravelmente com a redução de novos processos, diminuindo o grau de obstrução do Poder Judiciário e promovendo a pacificação social.

Por todo o exposto, é muito importante que iniciativas que envolvam a desjudicialização sejam estimuladas, promovendo a difusão de suas ideias para que haja amplo conhecimento da sociedade com relação à sua segurança e eficácia, mas principalmente, em prol de procedimentos menos burocráticos e com mais celeridade, com vistas ao aprimoramento do acesso à justiça.

\section{REFERÊNCIAS BIBLIOGRÁFICAS}

BELINETTI, Luiz Fernando. Tutela jurisdicional satisfativa. Revista de Processo, São Paulo, v. 21, n. 81, p. 98-103, jan./mar. 1996.

BRASIL. Constituição (1988). Constituição da República Federativa do Brasil. Brasília, DF: Senado, 1988.

CAPPELLETTI, Mauro; GARTH, Bryant. Acesso à justiça. Porto Alegre: Sergio Antônio Fabris, 1988.

CENEVIVA, Lei Dos Notários e Dos Registradores Comentada. 9ª Ed. São Paulo: Saraiva, 2014.

CONJUR. Atos em cartórios retiraram 1,3 milhão de processos da Justiça. Disponível em http://www.conjur.com.br/2016-jul-25/atos-cartorios-retiraram-13-milhao-processos-justica. Acesso em 25.07.2016.

CRUZ, Maria Luiza Póvoa. Separação, Divórcio e Inventário por via Administrativa:

Autonomia e Efetividade. In: DEL GUERCIO NETO, Arthur; DEL GUERCIO, Lucas Barelli (Coords.). et. al. Homenagem aos 10 anos da lei federal n $\mathrm{n}^{\mathrm{o}}$ 11.441/07 em 10 artigos. $1^{\mathrm{a}}$ Ed. São Paulo: YK Editora, 2017. p. 178-187.

DINAMARCO, Cândido Rangel; LOPES, Teoria Geral do Novo Processo Civil. São Paulo: Malheiros, 2016.

MELO, Diogo Soares Cunha. A tendência da extrajudicialização e a necessidade de traçar novos horizontes. In: DEL GUERCIO NETO, Arthur; DEL GUERCIO, Lucas Barelli (Coords.). et. al. Homenagem aos 10 anos da lei federal n $\mathrm{n}^{\mathrm{T}} 11.441 / 07 \mathrm{em} 10$ artigos. $1^{\mathrm{a}}$ Ed. São Paulo: YK Editora, 2017. p. 84-108. 
MENDES, Aluisio Gonçalves de Castro; SILVA, Larissa Clare Pochmann. Acesso à justiça: uma releitura da obra de Mauro Capelletti e Bryant Garth a partir do Brasil 40 anos depois. In Quaestio Juris. Vol. 08, nº. 03. Rio de Janeiro, 2015. pp. 1827-1858. Disponível em <http://www.e-publicacoes.uerj.br/index.php/quaestioiuris/article/view/19385>. Acesso em 22 jul. 2018.

MUNIZ, Tânia Lobo. O conflito, os modelos de solução, o acesso à justiça e a estrutura oficial de solução de conflitos. In Estudos de Direito Negocial e os mecanismos contemporâneos de resolução de conflitos. 1 ed. Birigui: Boreal, 2014.

NERY JÚNIOR, Nelson. Princípios do processo civil na Constituição Federal. São Paulo: Revista dos Tribunais, 2004.

NOBRE, Francisco José Barbosa Nobre. A usucapião administrativa no Novo Código de Processo Civil. Revista Jus Navegandi, Teresina, ano 20, n. 4202, 2 jan. 2015. Disponível em: $<$ https://jus.com.br/artigos/31454/a-usucapiao-administrativa-no-novo-codigo-deprocesso-civil>. Acesso em: 22 jul. 2018.

PEDROSO, João. Percurso(s) da(s) reforma(s) da administração da justiça - uma nova relação entre o judicial e o não judicial. Centro de Estudos Sociais, Observatório Permanente da Justiça Portuguesa, Coimbra, v. 171, p.1-43, abr. 2002. Disponível em: <http://www.ces.uc.pt/publicacoes/oficina/ficheiros/171.pdf>. Acesso em: 20 maio 2018.

SARDINHA, Cristiano de Lima Vaz. Cartórios e Acesso à Justiça: A Contribuição das Serventias Extrajudiciais para a Sociedade Contemporânea, como Alternativa ao Poder Judiciário. $1^{\text {a }}$ Edição. Bahia: Editora Jus Podivm, 2018.

SILVA, Marcelo Lessa da. A mediação no Direito Brasileiro e sua efetividade no âmbito das serventias extrajudiciais. In: Revista de Formas Consensuais de Solução de Conflito. Curitiba: v.2, n.2, p. 96 - 113. Jul/Dez., 2016. Disponível em:

<http://www.indexlaw.org/index.php/revistasolucoesconflitos/article/view/1572>. Acesso em 20 Jul. 2018.

SOUZA, Lígia Arlé Ribeiro de. A importância das serventias extrajudiciais no processo de desjudicialização. Revista Jus Navigandi, ISSN 1518-4862, Teresina, ano 16, n. 3029, 17 out. 2011. Disponível em: <https://jus.com.br/artigos/20242〉. Acesso em: 22 Jul. 2018.

SUTER, José Ricardo. CACHAPUZ, Rozane da Rosa. Mediação e conciliação como meios de resolução de conflitos e acesso à justiça. In: Formas consensuais de solução de conflitos I [Recurso eletrônico on-line] organização

CONPEDI/UdelaR/Unisinos/URI/UFSM/Univali/UPF/FURG; Coordenadores: Charlise Paula Colet Gimenez, Mariella Bernasconi - Florianópolis: CONPEDI, 2016, p. 58-75.

TARTUCE, Fernanda. Mediação nos Conflitos Civis. 4ª Edição. São Paulo: Método, 2018.

WATANABE, Kazuo. Acesso à Justiça e Sociedade Moderna. In: Caderno de Administração da Justiça - Planejamento Estratégico 2009. Porto Alegre: TRF - 4ª Região, 2009.

Revista Cidadania e Acesso à Justiça | e-ISSN: 2526-026X | Porto Alegre | v. 4 | n. 2 | p. 01 - 19 | Jul/Dez. 2018 
Política Pública do Poder Judiciário Nacional para tratamento adequado dos conflitos de interesses. Revista de Processo, São Paulo, ano 136, v. 195, maio. Revista dos Tribunais, 2011.

WEIZENMANN, Luiz Carlos Weizenmann. A escritura pública decorrente da lei 11.441/07 e seu registro. TUTIKIAN, Cláudia Fonseca; TIMM, Luciano Benetti; PAIVA, João Pedro Lamana. Novo direito imobiliário e registral - São Paulo: Quartier Latin, 2008. 